Nascimento, NC, Medeiros, HIR, Pereira, IC, Oliveira, RES, Medeiros, IL \& Medeiros Jr , FC. (2020). Preparation of biscuit with the flour of maracujá skin (Passiflora edulis). Research, Society and Development, 9(7): 1-16, e501974333.

\title{
Elaboração de biscoito com a farinha da casca do maracujá (Passiflora edulis)
}

Preparation of biscuit with the flour of maracujá skin (Passiflora edulis)

Preparación de galleta con la harina de la cáscara de la fruta de la pasión (Passiflora edulis)

Recebido: 08/05/2020 | Revisado: 10/05/2020 | Aceito: 14/05/2020 | Publicado: 23/05/2020

Nathalia Cardoso Nascimento

ORCID: http://orcid.org/0000-0003-0910-0991

Centro Universitário de Ciências e Tecnologia do Maranhão, Brasil

E-mail: eunathaliacardoso@gmail.com

Herbert Igor Rodrigues de Medeiros

ORCID: http://orcid.org/0000-0003-0478-9769

Universidade Federal da Paraíba

E-mail: igorpls_15@hotmail.com

Irislene Costa Pereira

ORCID: http://orcid.org/0000-0001-8993-2020

Universidade Federal do Piauí, Brasil

E-mail: irislleny_cx@hotmail.com

Renan Elan da Silva Oliveira

ORCID: http://orcid.org/0000-0002-4146-2581

Universidade Federal de Lavras, Brasil

E-mail: renanesoliveira@gmail.com

Iany Louise de Medeiros

ORCID: http://orcid.org/0000-0002-9139-875X

Universidade Federal de Campina Grande

E-mail: ianylouise43@gmail.com

Francisco Cesino de Medeiros Júnior

ORCID: http://orcid.org/0000-0002-3252-7830

Centro Universitário de Ciências e Tecnologia do Maranhão, Brasil

E-mail: cesinocaico@yahoo.com.br

\section{Resumo}

O maracujá, uma fruta bastante conhecida e comercializada, atualmente é alvo de estudos que evidenciam suas propriedades nutricionais, a citar da sua casca, rica em vitaminas, minerais e 
em fibra alimentar, especificamente pelas fibras solúveis, que trazem benefícios como o controle glicêmico e prevenção de doenças cardiovasculares. Em razão ao elevado índice do descarte das cascas do maracujá, a utilização da mesma em produtos de panificação se constitui como uma alternativa para evitar o seu desperdício, aproveitando a fruta em sua totalidade. O objetivo deste estudo foi a elaboração dos biscoitos com a farinha da casca do maracujá. Trata-se de um estudo experimental, transversal e quantitativo que foi desenvolvido nos laboratórios de Técnica Dietética e Análise Sensorial de Alimentos do Centro Universitário de Ciência e Tecnologia do Maranhão - UNIFACEMA, localizado na cidade de Caxias - MA. A análise sensorial do produto foi realizada com 62 avaliadores não treinados, utilizando a escala hedônica de 9 pontos e de intenção de compra de 5 pontos, mediante a assinatura do TCLE. Para determinar as condições microbiológicas do produto foi realizado a análise microbiológica. Os resultados obtidos mostram que das três amostras (A, B e C) desenvolvidas, duas (A e B) obtiveram aceitação por parte dos avaliadores. Os resultados da análise microbiológica indicaram que as três amostras estão de acordo com a legislação vigente. Portanto, a elaboração do biscoito mostrou-se como potencial tecnológico no mercado de panificação e como uma opção alimentar saudável, sustentável e econômico.

Palavras-chave: Maracujá; Aproveitamento tecnológico; Farinha; Biscoito.

\section{Abstract}

Passion fruit, a well-known and commercialized fruit, is currently the target of studies that show its nutritional properties, namely its bark, rich in vitamins, minerals and dietary fiber, specifically soluble fibers, which bring benefits such as glycemic control and prevention of cardiovascular diseases. Due to the high rate of disposal of passion fruit peels, the use of the same in bakery products is an alternative to avoid its waste, taking advantage of the fruit in its entirety. The aim of this study was to prepare the biscuits with the flour from the shell of the passion fruit. This is an experimental, cross-sectional and quantitative study that was developed in the laboratories of Dietary Technique and Sensory Analysis of Food of the University Center of Science and Technology of Maranhão - UNIFACEMA, located in the city of Caxias - MA. The sensory analysis of the product was performed with 62 untrained evaluators, using the 9-point hedonic scale and 5-point purchase intention, by signing the TCLE. Microbiological analysis was performed to determine the microbiological conditions of the product. The results obtained show that of the three samples (A, B and C) developed, two (A and B) obtained acceptance by the evaluators. The results of the microbiological analysis indicated that the three samples are in accordance with current legislation. Therefore, 
the preparation of the biscuit proved to be a technological potential in the bakery market and as a healthy, sustainable and economic food option.

Keywords: Passion fruit; Technological use; Flour; Biscuit.

\section{Resumen}

La fruta de pasión, una fruta conocida y comercializada, es actualmente el objetivo de estudios que muestran sus propiedades nutricionales, a saber, su corteza, rica en vitaminas, minerales y fibra dietética, específicamente fibras solubles, que aportan beneficios como el control glucémico y la prevención de enfermedades cardiovasculares. Debido a la alta tasa de eliminación de cáscaras de maracuyá, el uso de las mismas en productos de panadería es una alternativa para evitar sus residuos, aprovechando la fruta en su totalidad. El objetivo de este estudio fue preparar las galletas con la harina de la cáscara de la maracuyá. Se trata de un estudio experimental, transversal y cuantitativo que se desarrolló en los laboratorios de Técnica Dietética y Análisis Sensorial de Alimentos del Centro Universitario de Ciencia y Tecnología de Maranhao - UNIFACEMA, ubicado en la ciudad de Caxias - MA. El análisis sensorial del producto se realizó con 62 evaluadores no entrenados, utilizando la escala hedónica de 9 puntos y la intención de compra de 5 puntos, firmando el TCLE. Se realizaron análisis microbiológicos para determinar las condiciones microbiológicas del producto. Los resultados obtenidos muestran que de las tres muestras (A, B y C) desarrolladas, dos (A y B) obtuvieron la aceptación por parte de los evaluadores. Los resultados del análisis microbiológico indicaron que las tres muestras están de acuerdo con la legislación vigente. Por lo tanto, la preparación de la galleta resultó ser un potencial tecnológico en el mercado de la panadería y como una opción alimentaria saludable, sostenible y económica.

Palabras clave: Maracuyá; Utilización tecnológica; Harina; Galleta.

\section{Introdução}

O maracujá (Passiflora edulis), conhecido por seu amplo uso na medicina popular e na comercialização do suco, hoje, as propriedades da sua casca ganham destaque. Estudos têm evidenciado as suas propriedades funcionais, principalmente aquelas relacionadas ao teor e ao tipo de fibra (solúvel), fazendo com que a casca do maracujá não seja mais considerada um resíduo industrial, uma vez que pode ser utilizada na elaboração de novos produtos, denominados de coprodutos (Ramos et al., 2007; Córdova et al., 2005).

Neste sentido, o uso de farinhas mistas em alimentos se constitui como uma tecnologia 
alimentícia amplamente demonstrada e empregada na indústria. Com uma rica composição nutricional, a inserção de farinha feitas a base de coprodutos, surge como uma estratégia de orientação para o consumo do integral de frutos e como forma de oferecer nutrientes e suprir possíveis deficiências nutricionais, decorrente da mudança no padrão da alimentação das pessoas, que consomem cada vez mais alimentos industrializados em detrimento dos in natura, naturalmente ricos em fibras, vitaminas e minerais (Fasolini et al., 2007; Santana et al., 2011; Kaefer et al., 2013).

A farinha da casca do maracujá, consequentemente, também será rica nos compostos da casca, assim como cálcio, sódio e potássio, podendo ser utilizada como complemento em alimentos, enriquecendo-os, ou ainda, podendo ser usada na elaboração de novos produtos, tais como: biscoitos, pães, sopas, entre outros (Uchoa et al., 2008; Dias et al., 2016).

O biscoito, por exemplo, é obtido pelo amassamento e cozimento da massa preparada com farinhas e outros ingredientes, constituindo-se um produto de fácil incorporação de ingredientes alternativos. Além disto, é um tipo de produto que é comum aos lares dos brasileiros, além de ser de grande interesse comercial, devido à sua praticidade, relação custobenefício e longo tempo de prateleira. Contudo, possuem baixo valor nutricional, no qual o enriquecimento deste tipo de alimento com farinhas de cascas de frutas pode ser uma excelente alternativa para o reaproveitamento agroindustriais, agregando valor nutricional a um alimento bastante consumido pela população (Santos et al., 2017). Com base neste contexto, o objetivo do presente estudo foi elaborar biscoitos com a farinha da casca do maracujá.

\section{Metodologia}

Trata-se de um estudo do tipo experimental, de caráter transversal e de abordagem quantitativa como preconiza Pereira et al. (2018). Ele foi realizado no mês de outubro de 2019. Os espaços utilizados para essa finalidade foram os laboratórios de Técnica Dietética e Análise Sensorial de Alimentos, do Centro Universitário de Ciência e Tecnologia do Maranhão - UNIFACEMA, localizada em Caxias - MA.

O produto foi elaborado utilizando a matéria-prima farinha da casca do maracujáamarelo, seguindo um procedimento padrão para a elaboração do biscoito respeitando, neste processo, a adequação dos ingredientes utilizados na receita. Adicionalmente, após a formulação das amostras, foi realizado testes sensoriais. Quanto aos ingredientes, foram utilizados: farinha da casca do maracujá-amarelo, amido de milho, açúcar demerara, coco 
ralado, margarina e ovos, obtidos por meio do comércio local.

Para a elaboração dos biscoitos, a metodologia proposta foi adaptada de Santos et al. (2011). Realizou-se a princípio, a separação e pesagem dos ingredientes para cada tratamento. Posteriormemte, misturou-se a margarina, açúcar e os ovos, depois o coco ralado e por último, a quantidade formulada para cada amostra, composta por amido de milho e farinha da casca do maracujá. Com a massa uniforme, foram moldados e dispostos na assadeira no forno industrial a $180{ }^{\circ} \mathrm{C}$ por 20 minutos e armazenados em um recipiente higienizado em temperatura ambiente.

As formulações dos biscoitos foram desenvolvidas em três tipos de amostras, todas adicionadas a farinha da casca do maracujá, e a composição dos respectivos ingredientes de cada amostra, conforme a Tabela 1.

Tabela 1. Ingredientes utilizados para formular os biscoitos com a farinha da casca do maracujá (Plassifora edulis).

\begin{tabular}{llll}
\hline & \multicolumn{3}{c}{ Formulações } \\
\cline { 2 - 4 } Ingredientes & Amostra & Amostra & Amostra \\
& A & B & C \\
\cline { 2 - 4 } Amido de milho & 220 & 200 & 175 \\
Farinha da casca & $30(10 \%)$ & $50(20 \%)$ & $75(30 \%)$ \\
do Maracujá & 160 & 160 & 160 \\
Açúcar demerara & 30 & 30 & 30 \\
Coco ralado seco & 50 & 50 & 50 \\
Ovos & 100 & 100 & 100 \\
Margarina & &
\end{tabular}

Fonte: Adaptado de Santos et al. (2011).

As análises foram realizadas no Laboratório Multi II do Centro Universitário de Ciências e Tecnologia do Maranhão - UNIFACEMA, quanto a determinação de coliformes termotolerantes pela técnica de tubos múltiplos e contagem de bolores e leveduras pela técnica de plaqueamento e Salmonela spp de acordo com a metodologia proposta pela Association of Official Analytical Chemists (A.O.A.C, 2016). Os resultados obtidos foram comparados com os padrões microbiológicos estabelecidos pela legislação vigente no Brasil.

A análise sensorial do biscoito com a farinha da casca do maracujá (Passiflora edulis) 
foi realizada com assessores não treinados para teste de aceitação com Escala Hedônica, recrutados no Centro Universitário de Ciência e Tecnologia do Maranhão - UNIFACEMA. O teste sensorial utilizado para verificar a aceitação dos assessores foram a Escala Hedônica de nove pontos com teste de intenção de compra acoplado com Escala Hedônica de cinco pontos (Dutcoski, 2013).

Os assessores sensoriais não treinados foram estudantes e funcionários do UNIFACEMA, que foram abordados e convidados a participar da presente pesquisa, onde os mesmos foram informados sobre os objetivos do estudo e somente participaram após a aceitação e assinatura do Termo de Consentimento Livre e Esclarecido (TCLE).

Os dados obtidos foram quantificados e inseridos através de planilhas no programa Microsoft Excel 2013, calculado frequência simples e apresentados em forma de Tabelas e Figuras. Para comparação entre as amostras foi aplicada a Análise de Variância (ANOVA) e existindo diferença, foi aplicado o teste de média Tukey ao nível de 5\% de significância (Ibidem, 2013).

O projeto foi submetido e aprovado sobre o número CAAE: 15354619.6.0000.8007 e número do Parecer: 3.560.487, pelo comitê de Ética e através de submissão na Plataforma Brasil de acordo com as normas e pesquisa para seres humanos (Brasil, 2012).

\section{Resultados e Discussão}

A elaboração do biscoito com a farinha da casca do maracujá (Passiflora edulis) foi realizada com 62 avaliadores não treinados. Para traçar o perfil dos avaliadores, foi respondido um questionário sobre o consumo, frequência e conhecimento em relação ao maracujá e a farinha da casca. Os dados relacionados com o perfil dos avaliadores podem ser observados na Tabela 2. 
Research, Society and Development, v. 9, n. 7, e501974333, 2020

(CC BY 4.0) | ISSN 2525-3409 | DOI: http://dx.doi.org/10.33448/rsd-v9i7.4333

Tabela 2. Perfil dos avaliadores sensoriais do biscoito com a farinha da casca do maracujá (Passiflora edulis).

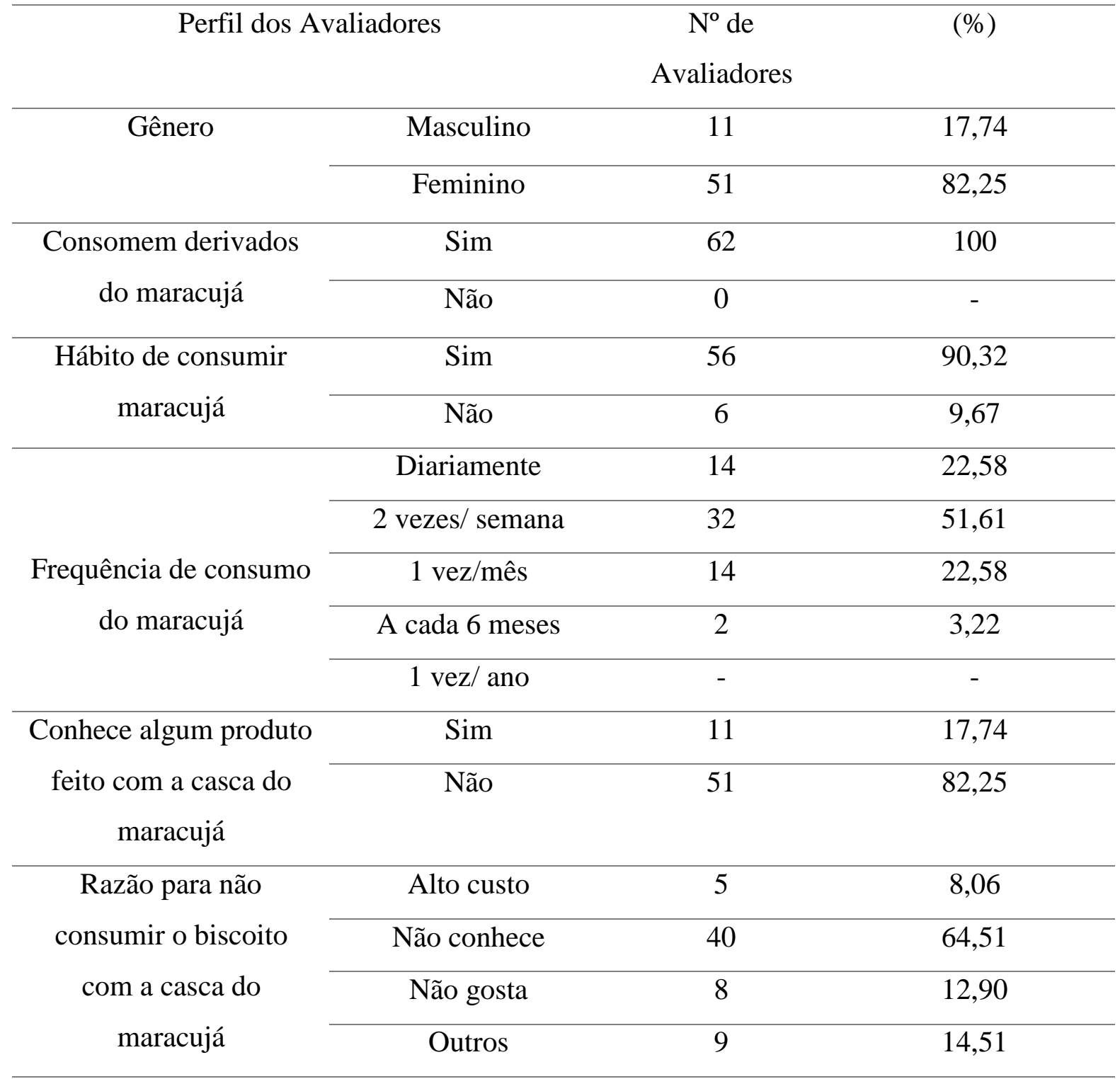

Fonte: Dados obtidos na pesquisa, 2019.

Dentre os 62 provadores, $82,25 \%$ foram do gênero feminino e $17,74 \%$ do gênero masculino, nos quais todos relataram o consumo do maracujá (100\%). A maioria dos participantes $(90,32 \%)$ possuíam o hábito de consumir o maracujá e ao serem questionados sobre a frequência do seu consumo, predominou o de até 2 vezes na semana, com mais de $70 \%$. Em relação ao conhecimento de algum alimento com a casca do maracujá, 82,25\% não conhecia. Por fim, ao serem perguntados sobre a possível razão para não consumir o biscoito com a farinha do maracujá, 64,51\% afirmaram não conhecer o produto. 
(CC BY 4.0) | ISSN 2525-3409 | DOI: http://dx.doi.org/10.33448/rsd-v9i7.4333

Corroborando com o presente estudo, no trabalho de Araújo et al. (2019) sobre o desenvolvimento de biscoitos a base de abóbora, ao traçar o perfil dos entrevistados, dentre os 54 provadores, $85,19 \%$ eram do gênero feminino e ao serem indagados quanto a frequência de consumo da abóbora, $44,44 \%$ consumiam 2 vezes por semana.

De acordo com Miranda et al. (2013), ao desenvolverem e analisarem bolos enriquecidos com farinha da casca do maracujá (Passiflora edulis) como fonte de fibras, ressaltaram a importância do aproveitamento integral dos alimentos na elaboração de produtos, os quais ainda são incomuns para o consumidor. Nesse estudo, $84 \%$ dos provadores nunca havia consumido ou desconhecia produtos elaborados com o aproveitamento integral de alimentos.

Na Tabela 3 estão os resultados dos valores médios e desvio padrão da análise sensorial do biscoito com a farinha da casca do maracujá (Passiflora edulis).

Tabela 3. Valores médios e desvio padrão da análise sensorial do biscoito com a farinha da casca do maracujá (Passiflora edulis).

\begin{tabular}{lccc}
\hline \multirow{2}{*}{ Atributos } & \multicolumn{3}{c}{ Amostras } \\
\cline { 2 - 4 } & $\mathrm{A}$ & $\mathrm{B}$ & $\mathrm{C}$ \\
\hline Aparência & $7,98 \pm 1,21 \mathrm{a}$ & $7,59 \pm 1,36 \mathrm{ab}$ & $7,09 \pm 1,53 \mathrm{~b}$ \\
Aroma & $7,45 \pm 1,50 \mathrm{a}$ & $7,13 \pm 1,54 \mathrm{ab}$ & $6,77 \pm 1,70 \mathrm{~b}$ \\
Textura & $7,85 \pm 1,39 \mathrm{a}$ & $7,69 \pm 1,12 \mathrm{a}$ & $6,51 \pm 1,79 \mathrm{~b}$ \\
Sabor & $8,30 \pm 1,02 \mathrm{a}$ & $7,42 \pm 1,59 \mathrm{~b}$ & $6,11 \pm 2,14 \mathrm{c}$ \\
Aceitação global & $8,33 \pm 0,79 \mathrm{a}$ & $7,53 \pm 1,63 \mathrm{~b}$ & $6,22 \pm 2,08 \mathrm{c}$ \\
\hline
\end{tabular}

*Médias seguidas na linha por letras iguais não apresentam diferença significativa pelo teste de tukey $(\mathrm{p} \leq 0,05)$.

Fonte: Dados obtidos na pesquisa, 2019.

Quanto ao atributo aparência, aroma e textura, houve diferenças entre as amostras A e C, sendo a amostra B estatisticamente igual as amostras A e C. Com relação ao sabor e a aceitação global do produto, as três amostras divergiram a 5\% de significância. Entre as amostras A e C, houve diferença estatística em todos os atributos avaliados.

A amostra A demonstrou-se com maiores valores, apresentando um resultado superior com nota 7 e 8 (gostei muito e gostei moderadamente). A amostra $\mathrm{C}$ (com maior teor da farinha da casca de maracujá) devido ao sabor amargo proeminente, reduziu a aceitação do biscoito, que obteve nota entre 7 e 6 (gostei moderadamente e gostei ligeiramente). 
No trabalho de Ozores, Storck \& Fogaça (2015), ao elaborarem bolos enriquecidos com a farinha da casca do maracujá (Plassifora edulis) com as concentrações de 5\%, $10 \%$ e $20 \%$ da farinha, concluíram que, quando a quantidade foi aumentada para $20 \%$ de farinha de maracujá, a aceitabilidade para todos os atributos diminuiu significativamente, provavelmente devido ao sabor amargo da farinha da casca do maracujá. A amostra mais aceita pelos avaliadores foi a que continha $5 \%$ a $10 \%$ da farinha de maracujá, com a nota entre 7 e 6 (gostei moderadamente e gostei ligeiramente), corroborando com o presente estudo.

Adicionalmente, no estudo de Rosolen et al. (2018) sobre a elaboração de cookies com a farinha da casca de laranja, nas proporções de 10\%, 20\% e 30\% da farinha, a nota 7 (gostei muito) evidenciou a aceitabilidade sensorial do sabor, aparência e textura. Ainda, os biscoitos com maior índice de aceitabilidade foram os com 10 e $20 \%$ e os com menor índice de aceitabilidade foi o com $30 \%$ de farinha de casca de laranja.

Ao adicionarem a farinha da casca de maracujá em bolos de milho, Maia et al. (2018) observaram uma diferença significativa em um nível de 5\% entre as médias de aceitação global, entre todas as formulações testadas, sendo que os valores hedônicos decresceram à medida que foi aumentando o teor de farinha de maracujá adicionado à formulação. Confirmando com este estudo que, quanto maior a quantidade de farinha utilizada em produtos de panificação, menor será a aceitação do produto, devido ao sabor forte e marcante da farinha da casca de maracujá.

Na Figura 1, encontra-se as porcentagens dos biscoitos, na escala hedônica mista, com os requisitos: aceitação, neutralidade e rejeição para cada amostra, afim de identificar a aceitação dos avaliadores em relação a intenção de compra do biscoito com a farinha da casca do maracujá (Passiflora edulis). 
Figura 1. Intenção de Compra do biscoito com a farinha da casca do maracujá (Passiflora edulis).

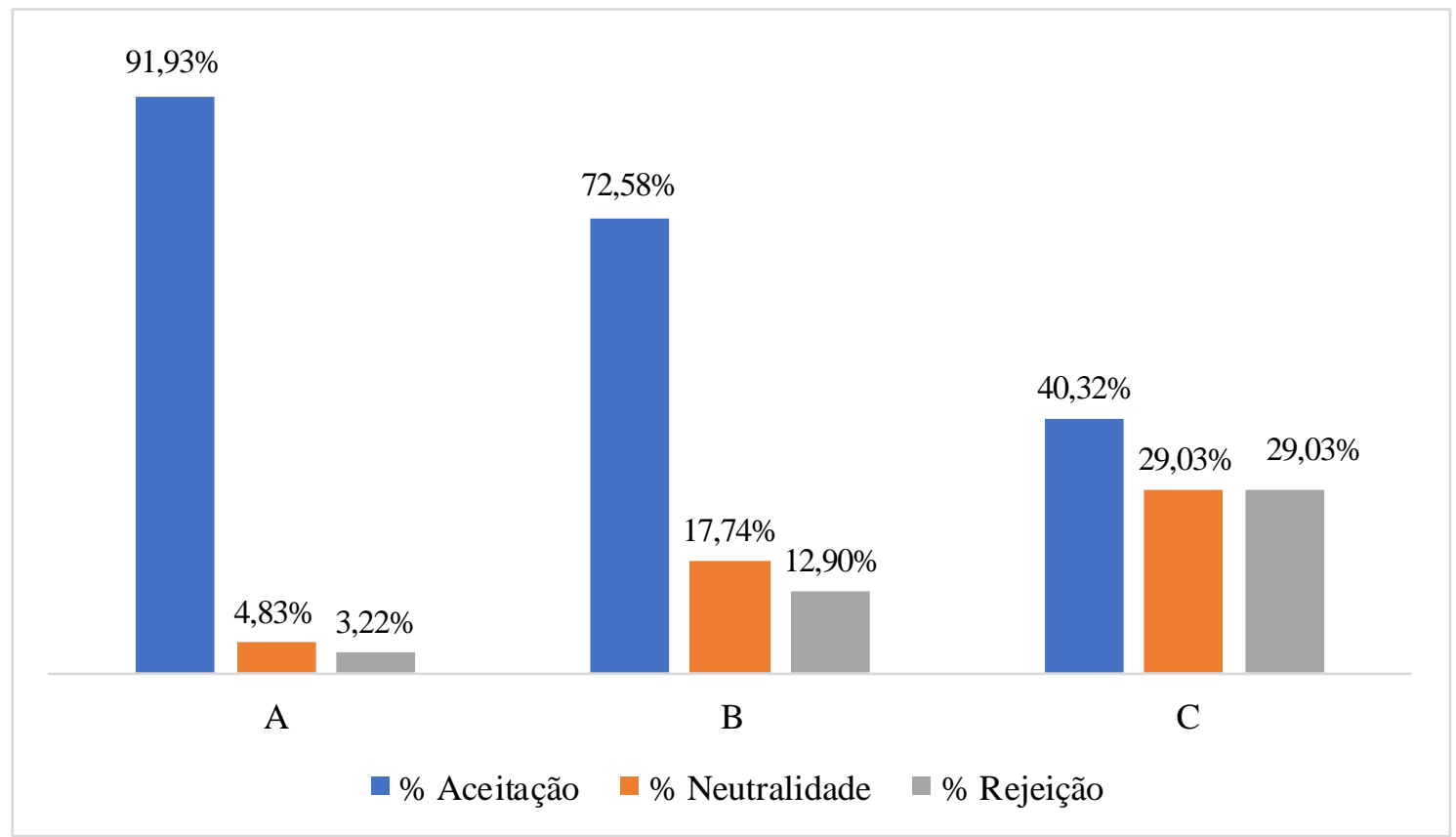

Escala hedônica mista de 5 pontos: Rejeição:1= Certamente não compraria; $2=$ Possivelmente não compraria; Neutralidade: $3=$ Talvez comprasse/ Talvez não comprasse; Aceitação: 4= Possivelmente compraria; 5= Certamente compraria.

Fonte: Dados obtidos na pesquisa, 2019.

Com os resultados obtidos, pôde-se observar que a amostra com maior percentual de intenção de compra foi a amostra A, com 91,93\% de aceitação, pois apresentava a menor concentração e sabor mais suave, com $10 \%$ da farinha da casca do maracujá.

A amostra B também foi aceita pelos avaliadores, com 72,58\% de intenção de compra, no qual apresentou mais concentração da farinha da casca de maracujá do que a amostra $\mathrm{A}$, com $20 \%$ da farinha. Devido a maior concentração de farinha da casca de maracujá (30\%), com sabor amargo acentuado, a amostra $C$ foi a que obteve o maior percentual de rejeição e neutralidade com $29,03 \%$ e aceitação de apenas $40,32 \%$ dos avaliadores.

Com o objetivo de elaborar um cookie com adição de diferentes níveis de farinha de resíduos de guavira (FRG) e avaliar a aceitabilidade sensorial, Medino et al. (2019) formularam cinco amostras, 2,5\% (F2), 5\% (F3), 7,5\% (F4) e 10\% (F5) de FRG. Os resultados evidenciaram que a menor aceitação das amostras adicionados de FRG ocorre em razão do sabor forte e cítrico da fruta.

Validando-se com o presente estudo, os cookies com maiores teores de farinha de guavira apresentaram uma coloração mais escura, efeito justificado pela cor amarronzada da 
farinha e por sua capacidade de retenção de água das fibras insolúveis, fato que aproxima as moléculas e deixa a cor do produto mais concentrada.

Ratificando-se com este estudo, Filho et al. (2018) ao desenvolverem brownies utilizando a farinha do mesocarpo externo do pequi (FCP), no atributo intenção de compra, mostraram que as amostras com maior teor da FCP (37,5\% e 50\%) não obtiveram boas notas, relacionado ao sabor amargo proeminente, que são mais notáveis nas amostras que possuem maior quantidade.

Segundo Dutcosky (2013), para que um produto seja considerado aceito no que diz respeito às suas características sensoriais, é necessário que o produto obtenha um índice de aceitabilidade de no mínimo $70 \%$. Frente a isto e de acordo com os resultados demonstrados, o presente estudo apresentou duas amostras (A e B) com porcentagens superiores a 70\%, confirmando, então, como um produto aceito pelos avaliadores.

Ainda, a Tabela 4 demonstra os resultados da análise microbiológica da amostra A, B e C do biscoito com farinha da casca do maracujá (Passiflora edulis).

Tabela 4. Análise microbiológica das amostras do biscoito com a farinha da casca do maracujá (Passiflora edulis).

\begin{tabular}{clcl}
\hline Amostras & \multicolumn{1}{c}{ Determinação } & Resultados & \multicolumn{1}{c}{ Padrões } \\
\hline \multirow{3}{*}{ A } & Coliformes a $45^{\circ} \mathrm{C}(\mathrm{NMP} / \mathrm{g})$ & $<3,0(\mathrm{NMP} / \mathrm{g})$ & $5 \times 10^{2}(\mathrm{NMP} / \mathrm{g})$ \\
\cline { 2 - 4 } & Fungos e Leveduras $(\mathrm{UFC} / \mathrm{g})$ & $<1,0 \times 10^{1}$ & - \\
\cline { 2 - 4 } & Salmonella ssp. & Ausência & Ausência em $25 \mathrm{~g}$ \\
\hline \multirow{3}{*}{ B } & Coliformes a $45^{\circ} \mathrm{C}(\mathrm{NMP} / \mathrm{g})$ & $<3,0(\mathrm{NMP} / \mathrm{g})$ & $5 \times 10^{2}(\mathrm{NMP} / \mathrm{g})$ \\
\cline { 2 - 4 } & Fungos e Leveduras $(\mathrm{UFC} / \mathrm{g})$ & $<1,0 \times 10^{1}$ & - \\
\cline { 2 - 4 } & Salmonella ssp. & Ausência & Ausência em $25 \mathrm{~g}$ \\
\hline \multirow{3}{*}{ C } & Coliformes a $45^{\circ} \mathrm{C}(\mathrm{NMP} / \mathrm{g})$ & $<3,0(\mathrm{NMP} / \mathrm{g})$ & $5 \times 10^{2}(\mathrm{NMP} / \mathrm{g})$ \\
\cline { 2 - 4 } & Fungos e Leveduras $(\mathrm{UFC} / \mathrm{g})$ & $<1,0 \times 10^{1}$ & - \\
\cline { 2 - 4 } & Salmonella ssp. & Ausência & Ausência em $25 \mathrm{~g}$
\end{tabular}

Fonte: Dados da pesquisa, 2019; Brasil, 2001.

De acordo com a Tabela 4, todas as amostras obtiveram valores dentro dos padrões para Coliformes a $45{ }^{\circ} \mathrm{C}$ (NMP/g), Fungos e Leveduras (UFC/g), bem como ausência de Salmonella ssp. Frente a isto, as três formulações dos biscoitos ficaram de acordo com as 
(CC BY 4.0) | ISSN 2525-3409 | DOI: http://dx.doi.org/10.33448/rsd-v9i7.4333

normas da Resolução $\mathrm{n}^{\circ}$. 12 de 02 de janeiro de 2001, que estabelece os padrões microbiológicos para biscoito sem recheio (Brasil, 2001).

Corroborando com esse resultado, Maia et al. (2018) ao analisarem microbiologicamente três amostras de bolo de milho com a farinha da casca do maracujá, constataram que todas as amostras estavam com valores abaixo para coliformes a $45^{\circ} \mathrm{C}(<3,0$ NMP/g) e ausência de Salmonella ssp. (25 g da amostra).

Amaral et al. (2019) apresentaram os mesmos resultados na análise de biscoitos desenvolvidos com especiarias, farinha de milho e semente de abóbora, em que as três formulações do biscoito apresentaram tubos negativos de coliformes totais e coliformes termotolerantes, sendo expressos em $<3,0 \mathrm{NMP} / \mathrm{g}$. E a Salmonella ssp. estava ausente nas amostras.

Ao analisar os parâmetros microbiológicos de biscoitos com a adição de farinha de feijão caupi, Fiorentin et al. (2019) mostraram que os biscoitos elaborados estavam compatíveis com os exigidos na legislação. Nas análises, a Salmonella ssp. esteve ausente em todas as formulações. Já os coliformes termotolerantes a $45^{\circ} \mathrm{C}$ e totais apresentaram valores de $<3,0 \mathrm{NMP} / \mathrm{g}$ em todas as amostras. Sendo assim, o produto desenvolvido não traz risco aos seus consumidores.

Diante do exposto, é possível observar a concordância entre os resultados obtidos e os dados disponíveis na literatura acerca da aceitação de produtos alimentícios com potencial functional e isto, deve-se a busca da população por produtos com benefícios a saúde. Um ponto importante trata-se da segurança deste alimento, em vista que não foi identificado presença de microrganismos patogênicos. Com isto, o presente trabalho demonstra a importância do reaproveitamento da casca do maracujá na fabricação de produtos inovadores, uma vez que se constitui como uma ótima alternativa para evitar o seu desperdício e para o aproveitamento em sua totalidade.

\section{Considerações Finais}

Após os resultados, os biscoitos estavam seguros do ponto de vista microbiológico, sem risco a saúde dos avaliadores. A padronização na elaboração dos biscoitos foi de suma importância na aceitação do produto, confirmando que as amostras com as menores concentrações da farinha, obtiveram maiores valores na Escala Hedônica, e portanto, o produto elaborado demonstrou-se com potencial tecnológico no mercado de panificação.

Diante disto, o desenvolvimento do presente estudo possibilitou a elaboração de um 
produto alimentício sustentável em função da farinha da casca de maracujá (Passiflora edulis), destacando-se na utilização dos coprodutos na indústria alimentícia.

Alem disto, o produto evidenciou-se como uma opção alimentar saudável e alternativo a pessoas com restrições alimentares, no entanto, sugere-se novos estudos para melhorar a aceitabilidade de produto a base da farinha da casca do maracujá, assim como caracterizar quanto a parâmetros físico-químicos.

\section{Referências}

Amaral, FA, Ferreira, IM, Santos, LVN, Silva, MOS, Fagundes, AA \& Carvalho, MG. (2019). Biscoito com especiarias e farinhas de milho e semente de abóbora: desenvolvimento e avaliação da qualidade. Revista DEMETRA, Alimentos, Nutrição e Saúde, 14(2), 250-259. doi: 10.12957/demetra.2019.33380.

Araújo, BCO, Pereira, IC, Nascimento, NC, Oliveira, RES \& Junior, FCM. (2019). Desenvolvimento de biscoito a base de abóbora (Cucurbita spp.). Revista Pesquisa, Sociedade e Desenvolvimento, 8(7), 933-946. doi: 10.33448/rsd-v8i7.1128.

Association Of Official Analytical Chemists- AOAC. (2016). Official methods of analysis, Gaithersburg: USA.

Brasil, Resolução $\mathrm{n}^{\circ}$ 12, de 02 de janeiro de 2001. (2001). Dispõe sobre os princípios gerais para o estabelecimento de critérios e padrões microbiológicos para alimentos. Agência Nacional de Vigilância Sanitária (ANVISA). Acesso em: 15 abril 2020. Disponível em: http://portal.anvisa.gov.br/documents/33880/2568070/RDC_12_2001.pdf/15ffddf6-37674527-bfac-740a0400829b.

Brasil. (2012). Resolução n. 466, de 12 de dezembro de 2012. Aprova diretrizes e normas regulamentadoras de pesquisas envolvendo seres humanos. Brasília, Diário Oficial da União, 12 dez. 2012. Acesso em: 11 maio 2020. Disponível em: http://www.conselho.saude.gov.br/resolucoes/2012/Reso466.pdf. 
Córdova, KV, Gama, TMT, Winter, CMG, Kaskantzis, NG \& Freitas, RJS. (2005). Características físico-químicas da casca de maracujá amarelo (Passiflora edulis flavicarpa Deg) obtida por secagem. Revista Boletim Centro de Pesquisa de Processamento de Alimentos (CEPPA), 23(2), 221-230. doi: 10.5380/cep.v23i2.4491.

Dias, HJ, Silva, MDL, Santos, IHVS, Souza, ATR, Monge, SM, Veloso, FB \& Oliveira, CR. (2016). Caracterização sensorial e nutricional de bolo mousse de maracujá isento de glúten. Revista Saber Científico, 5(1), 69-80.

Dutcosky, SD. (2013). Análise sensorial de alimentos. Curitiba: Champagnat.

Fasolini, LH, Almeida, GC, Castanho, OS \& Netto-Oliveira, ER. (2007). Biscoitos produzidos com farinha de banana: avaliações química, física e sensorial. Revista Ciência Tecnologia de Alimentos, 27(3), 524-529. doi: 10.1590/S0101-20612007000300016

Fiorentin, SD, Teixeira, FR, Silva, SZ, Bernadi, DM, Santos, SMV \& Lovato, FR. (2019). Desenvolvimento de formulações biscoitos tipo cookies com adição de farinha de feijão caupi brs xiquexique. Revista FAG, Journal of Health, 1(2), 36-48. doi: 10.35984/fjh.v1i2.85.

Filho, RJ, Lustosa, IBS, Sampaio, RMM, Moreira, MR, Morais, VD \& Souza, VSS. (2018). Melhoria do valor nutricional do brownie utilizando farinha do mesocarpo externo do pequi (Caryocar brasiliense camb). Revista Motricidade, 14(1), 196-204.

Kaefer, S, Fogaça, AO, Storck, CR \& Kirsten, VR. (2013). Bolo com farinha de pupunha (Bactris gasipaes): análise da composição centesimal e sensorial. Revista Alimentos $e$ Nutrição, 24(3), 347-352.

Maia, CMPC, Pontes, DF, Garrun, DS, Oliveira, MN, Arcanjo, SRS \& Chinelate, CB. (2018). Farinha de maracujá na elaboração de bolo de milho. Revista Verde, 13(3), 328-336. doi: 10.18378/rvads.v13i3.5678. 
Medino, IC, Tonini, IGO, Amaral, LA, Loubet Filho, PS, Santos, EF \& Novello, D. (2019). Cookie adicionado de farinha de resíduos de guavira: composição físico-química e análise sensorial. Revista Evidência, 19(1), 7-22. doi: 10.18593/eba.v19i1.20287.

Miranda, AA, Caixeta, ACA, Flávio, EF \& Pinho, L. (2013). Desenvolvimento e análise de bolos enriquecidos com farinha da casca do maracujá (Passiflora edulis) como fonte de fibras. Revista Alimentos e Nutrição, 24(2), 225-232.

Ozores, B, Storck, CR \& Fogaça, AO. (2015). Aceitabilidade e características tecnológicas de bolo enriquecido com farinha de maracujá. Disciplinarum Scientia, 16(1), 61-69.

Pereira, AS, Shitsuka, DM, Parreira, FJ \& Shitsuka, R. (2018). Metodologia da pesquisa científica. [e-book]. Santa Maria. Ed. UAB/NTE/UFSM. Disponível em: https://repositorio.ufsm.br/bitstream/handle/1/15824/Lic_Computacao_MetodologiaPesquisa-Cientifica.pdf?sequence $=1$.

Ramos, AT, Cunha, MAL, Sabaa-Srur, AUO, Pires, VCF, Cardoso, MAA, Diniz, MFM \& Medeiros, CCM. (2007). Uso de Passiflora edulis f. flavicarpa na redução do colesterol. Revista Brasileira de Farmacognosia, 17(4), 592-597. doi: 10.1590/S0102695X2007000400019.

Rosolen, MD, Bresciani, L, Sprandel, CL, Spader, M, Klein, AL \& Wollmuth, JOM. (2018). Biscoitos tipo cookies desenvolvidos a partir de farinha de casca de laranja. Revista Destaques Acadêmicos, 10(4), 8-17. doi: 10.22410/issn.2176-3070.v10i4a2018.1711.

Santana, FC, Silva, JV, Santos, AJAO, Alves, AR, Wartha, ERSA, Marcellini, OS \& Silva, MAAP. (2011). Desenvolvimento de biscoito rico em fibras elaborado por substituição parcial da farinha de trigo, por farinha da casca do maracujá amarelo (Passiflora edulis flavicarpa) e fécula de mandioca (Manihot esculenta crantz). Revista Alimentos e Nutrição, 22(3), 391-99.

Santos, AAO, Santos, AJAO, Alves, AR, Santana, FC, Silva, JV 7 Marcellini, PS. (2011). Elaboração de biscoitos a partir da incorporação de produtos da mandioca e casca de maracujá (Passiflora edulis Flavicarpa) na farinha de trigo. Revista Scientia Plena, 7(8), 235-342. 
Santos, AKDC, Rodrigues, EC, Hernandes, T \& Oliveira, AP. (2017). Caracterização física e química de biscoito salgado enriquecido com farinha de resíduos do processamento da cenoura e especiarias. Revista Brasileira Tecnológica de Agroindustria, 11(2), 2368-2381. doi: $10.3895 /$ rbta.v11n2.3062.

Uchoa, AMA, Costa, JD, Maia, GA, Silva, EMC, Carvalho, AFFU \& Meira, TR. (2008). Parâmetros físico-químicos, teor de fibra bruta e alimentar de pós alimentícios obtidos de resíduos de frutas tropicais. Revista Segurança Alimentar e Nutricional, 15(2), 58-65. doi: 10.20396/san.v15i2.1817.

\section{Porcentagem de contribuição de cada autor no manuscrito}

Nathalia Cardoso Nascimento - 25\%

Herbert Igor Rodrigues de Medeiros - 15\%

Irislene Costa Pereira $-15 \%$

Renan Elan da Silva Oliveira - 15\%

Iany Louise de Medeiros - 15\%

Francisco Cesino de Medeiros Júnior - 15\% 